\title{
Utilization of Iron-Medium Chain Fatty Acid Complexes in Growing Rats
}

\author{
Mitsuhiro Furuse, Sung Ik Yang, Masaharu Hayashi* \\ and Jun-ichi OKUMURA \\ Laboratory of Animal Nutrition, School of Agriculture, \\ Nagoya University, Chikusa-ku, Nagoya-shi 464-01 \\ * Wakayama Research Laboratories, Kao Corp., \\ Wakayama-shi 640
}

(Received November 11, 1992)

Key words : iron-medium chain fatty acid, iron, rat, absorption

Medium chain fatty acids (MCFAs) are composed of caproic $(6: 0)$, caprylic $(8: 0)$, capric $(10: 0)$ and lauric $(12: 0)$ acids ${ }^{1)}$. The metabolism of MCFAs is largely different from long chain fatty acids (LCFAs). For instance, the path for the transport of MCFAs in the rat is different from that of LCFAs, because the former is transported via the portal vein and lymph and the latter entirely in the lymph ${ }^{2)}$. After transport to the liver, MCFAs are quickly oxidized and are not incorporated in the lipid ester moieties of lipoproteins ${ }^{8}$. In the previous study, the efficacy of iron-medium chain fatty acid complexes on the prevention of anemia in pregnant rats was investigated ${ }^{7)}$, but no significant improvement was observed in iron contents of serum and tissues compared with iron-long chain fatty acid complexes and ferric citrate. Conversely, the lower absorption rate of iron-medium chain fatty acid complex was suggested by the serum ferritin concentration.

The present study was conducted to clarify whether or not the absorption and retention of iron was altered by the form of medium chain fatty acid complex in growing rats.

\section{Materials and Methods}

Animals and diets: Five-week-old Wistar rats (ST strain) were purchased from Japan SLC Inc. (Hamamatsu). The animals were housed individually in wire-mesh cages in a controlled environment $\left(24^{\circ} \mathrm{C}\right)$ with a 12 -hr (0500-1700) light cycle. Rats were ranked by body weight and divided into four treatment groups of five rats each to equalize initial body weight among treatments.

Four experimental diets were designed to contain equivalent iron levels. The composition of an experimental diet was described previously ${ }^{7)}$. The reference group was fed a diet containing ferric citrate $(0.210 \mathrm{~g} / \mathrm{kg}$ diet $)$. Other three groups (two iron-medium chain fatty acids and one iron-long chain fatty acid complexes) were given diets containing iron as iron-caprylic acid complex (C 8-Fe, 0.299 $\mathrm{g} / \mathrm{kg}$ ), iron-lauric acid complex (C 12- $\mathrm{Fe}, 0.446$ $\mathrm{g} / \mathrm{k})$ or iron-palmitic acid complex (C 16-Fe,

成長中のラットに扔ける鉄-中銷脂肪酸複合体の利用性：古瀬充宏・梁 昆益・林 正治* ・奥村純市 (名古室大学 農学部 名古屋市干種区 $464-01, *$ 花王和歌山研究所 和歌山市 640 )

Anim. Sci. Technol. (Jpn.) 64 (8) : 816-818 816 
$0.495 \mathrm{~g} / \mathrm{kg})$.

Experimental procedure: Rats were given respective diets ad $l i b$. and allowed free access to iron-free distilled water for 10 days. The feces and urine were collected individually during the last 3 days of the experimental period. Feces were air-dried at $55^{\circ} \mathrm{C}$ and ground for analysis and urine was frozen at $-20^{\circ} \mathrm{C}$ until analysis. At the final day of the experiment, rats were sacrificed by decapitation under diethyl ether anesthetization and blood sample was obtained. Serum iron concentration was determined by using a kit (Automate $\mathrm{Fe}$ (AZ), Sinotest, Tokyo). After killing animals, the liver and spleen were removed immediately and blotted and weighed. These samples were ashed with an electric muffle at $550^{\circ} \mathrm{C}$. Feces and urine were ashed with nitric and sulfuric acids. Iron contents of the organs, feces and urine were determined by using an inductively coupled plasma emission spectrometry (ICAP-575, Nippon JarrellAsh, Tokyo).
Statistical procedure: Data were subjected to analysis of variance, and significance of difference between means was determined by the DUNCAN's multiple range test ${ }^{33}$ using a commercially available statistical package ${ }^{9 \text { ) }}$.

\section{Results and Discussion}

Table 1 shows the effect of iron-medium chain fatty acids complexes on the iron metabolism in growing rats. The food intake was significantly lower in the $\mathrm{C} 8 \mathrm{Fe}$ group than in other groups, but iron contents in the liver and spleen and serum iron concentration were not different among treatments. So far, we have reported that the food intakes were decreased by dietary medium chain triglyceride (MCT) compared with dietary long chain triglyceride (LCT) in both growing rats ${ }^{4)}$ and chicks $^{5,6)}$. These effects were induced by large amounts of MCT (more than 18 percent in the diet). However, the reduction of food intake in MCT diet could not be explained by the difference in the palatability between LCT and

Table 1. Iron content in tissues and iron balance of growing rats fed diets containing iron-medium chain fatty acid complexes

\begin{tabular}{|c|c|c|c|c|c|}
\hline & Control & $\mathrm{C} 8-\mathrm{Fe}$ & $\mathrm{C} 12-\mathrm{Fe}$ & $\mathrm{C} 16-\mathrm{Fe}$ & Pooled SEM \\
\hline Food intake ( $\mathrm{g} / 10$ days) & $166^{\wedge}$ & $145^{\mathrm{B}}$ & $165^{\mathrm{A}}$ & $162^{\mathrm{A}}$ & 5.2 \\
\hline Body weight gain (g/10 days) & 69.0 & 60.6 & 67.8 & 69.2 & 2.99 \\
\hline Liver weight $(g)$ & 11.4 & 9.6 & 10.7 & 11.4 & 0.57 \\
\hline Liver iron content (mg/liver) & 0.497 & 0.507 & 0.532 & 0.402 & 0.0469 \\
\hline Spleen $(g)$ & 0.532 & 0.478 & 0.532 & 0.520 & 0.0280 \\
\hline Spleen iron content (mg/spleen) & 0.0583 & 0.0577 & 0.0641 & 0.0568 & 0.0051 \\
\hline Serum iron $(\mu \mathrm{g} / 100 \mathrm{~m} l)$ & 293 & 246 & 254 & 291 & 19.7 \\
\hline Iron intake ( $\mathrm{mg} / 3$ days) & 2. $10^{A}$ & $1.50^{\mathrm{C}}$ & $1.93^{\mathrm{AB}}$ & $1.81^{\mathrm{B}}$ & 0.063 \\
\hline Fecal iron excretion ( $\mathrm{mg} / 3$ days) & 0.56 & 0.48 & 0.54 & 0.55 & 0.0516 \\
\hline Iron absorption ( $\mathrm{mg} / 3$ days) & 1. $54^{\mathrm{A}}$ & $1.02^{\mathrm{C}}$ & 1. $38^{\mathrm{B}}$ & 1. $25^{\mathrm{B}}$ & 0.053 \\
\hline Iron absorption rate $(\%)^{*}$ & 73.4 & 67.8 & 72.4 & 69.5 & 2.43 \\
\hline Urinary iron excretion ( $\mathrm{mg} / 3$ days) & 0.009 & 0.015 & 0.007 & 0.009 & 0.0031 \\
\hline Iron balance ( $\mathrm{mg} / 3$ days) & 1. $54^{\mathrm{A}}$ & $1.00^{\mathrm{c}}$ & 1. $38^{\mathrm{B}}$ & 1. $24^{\mathrm{B}}$ & $0.05 \%$ \\
\hline Iron retention rate $(\%) *$ & 73.0 & 66.8 & 72.0 & 69.0 & 2. 42 \\
\hline
\end{tabular}

${ }^{A-C}$ Means having different superscript letters are significantly different at $P<0.05$.

"Iron absorption $\times 100 /$ iron intake.

* Iron balance $\times 100$ /iron intake.

Abbreviations: $\mathrm{C} 8-\mathrm{Fe}$, iron-caprylic acid complex; $\mathrm{C} 12-\mathrm{Fe}$, iron-lauric acid complex; $\mathrm{C} 16-\mathrm{Fe}$, iron-palmitic acid complex. 
MCT in rats ${ }^{4}$. Only a small amount of $\mathrm{C} 8-\mathrm{Fe}$ induced the reduction in food intake in the present study. The palatability of medium chain fatty acids would be different between the triglyceride and iron salt forms. The reduction of food intake due to iron-medium chain fatty acid complex could be explained, partly but not entirely, by the palatability of iron-medium chain fatty acids. For example, caprylic acid has a slightly unpleasant smell and taste, and consequently food intake might be reduced. The different responses of food intake by iron sources influenced the iron intake in growing rats. The lower iron intake directly caused the lower absorption and balance of iron in the $\mathrm{C} 8-\mathrm{Fe}$ group, because iron absorption rate and retention rate were not significantly different compared with the control diet. In general, the efficiency of iron absorption increases in iron deficiency ${ }^{10)}$. The reason for the discrepancy remained unclear. To equalize the food intake among dietary treatments is important to investigate the mineral metabolism. On the other hand, we think that to investigate the response and behavior of animals for the experimental diet under an $a b$ lib. feeding is also important. In any event, it was concluded that the usage of iron-medium chain fatty acid complex was not advantage as an animal feed at the present time.

\section{Reference}

1) Bach, A. and V. K. Babayan, Medium- chain triglyceride: an update. Am. J. Clin. Nutr., 36 : 950-962. 1982.

2) Bloom, B., I. L. Chaikoff and W. 0. REINHARDT, Intestinal lymph as pathway for transport of absorbed fatty acids of different chain lengths. Am. J. Physiol., 166 : 451-455. 1951.

3) Duncan, D. B., Multiple range and multiple $F$ tests. Biometrics, 11: 1-42. 1955.

4) Furuse, M., Y. H. Choi, R. T. Mabayo and J. OKumura, Feeding behavior in rats fed diets containing medium chain triglyceride. Physiol. Behav., 52: 815-817. 1992.

5) Furuse, M., R. T. Mabayo, Y. H. Chor, D. M. Densow and J. Okumura, Feeding behavior in chickens given diets containing medium chain triglyceride. Br. Poult. Sci., 34 : 211-217. 1993.

6) Furuse, M., R. T. Mabayo, K. Kita and J. OKumura, Effect of dietary medium chain triglyceride on protein and energy utilization in growing chicks. Br. Poult. Sci., $33:$ 49-57. 1992.

7) Furuse, M., S. I. Yang, M. HaYashi, T. IWASAKI and J. OKUMURA, Effect of ironmedium chain fatty acid complexes on iron metabolism in pregnant rats. Anim. Sci., Technol. (Jpn.), 63: 912-916. 1992.

8) Hashim, S. A. and P. Tantibhedyangkul, MCT in early life: effects on growth of adipose tissue. Lipids, $22:$ 429-434. 1987.

9) SAS User's Guide: Statistics. SAS Institute Inc, Cary, NC. 1985.

10) UNDERWOOD, E. J., Trace Elements in Human and Animal Nutrition. Fouth edition. 13-55. Academic Press. London. 1977. 